\title{
Attitudes regarding carrier testing in incompetent children: a survey of European clinical geneticists
}

\author{
Pascal Borry ${ }^{*, 1}$, Tom Goffin ${ }^{1}$, Herman Nys ${ }^{1}$ and Kris Dierickx ${ }^{1}$ \\ ${ }^{1}$ Centre for Biomedical Ethics and Law, Katholieke Universiteit Leuven, Leuven, Belgium
}

The aim of this study is to gather information from European clinical geneticists about their practices and attitudes with regard to carrier testing in incompetent children. European clinical institutes where genetic counseling is offered to patients have been contacted. One hundred and seventy-seven of the 287 eligible respondents, corresponding to a response rate of $63 \%$, completed the questionnaire. For all autosomal recessive and $\mathrm{X}$-linked disorders studied, the majority of the respondents were very unwilling or unwilling to provide a carrier test to a 6-year-old asymptomatic child on parental request (range $73-91 \%$ ). The results of the Wilcoxon-Mann-Whitney $U$ test indicated that for almost all disorders, respondents from Eastern and Southern European countries are more willing to provide a carrier test to a 6-year-old asymptomatic child than respondents from Western and Northern European countries. The Spearman's rank correlation coefficients showed that when a clinical geneticist was unwilling to perform such a test, he/she mostly disagreed that parental uncertainty and anxiety was a good reason to perform a carrier test, he/she mostly disagreed that parents should have the right to decide about such a test, he/she mostly agreed that future autonomy and the confidentiality of genetic information is violated if this test is performed. Overall, the survey showed an adherence to existing recommendations and guidelines regarding carrier testing in incompetent minors. However, for every condition studied, a group of clinical geneticists was willing or very willing to provide a carrier test to a 6-year-old child on parental request. European Journal of Human Genetics (2007) 15, 1211-1217; doi:10.1038/sj.ejhg.5201909; published online 22 August 2007

Keywords: genetic testing; carrier testing; genetic counseling; attitudes

\section{Introduction}

In a previous publication, ${ }^{1}$ we discussed the recommendations regarding carrier testing in minors (ie, people who have not reached legal majority) from 14 guidelines and position papers emanating from genetic associations and societies, medical and pediatric associations and institutes, government-related organizations and a consumer group. All guidelines retrieved were in agreement that tests to determine carrier status in healthy unaffected children or adolescents ideally should be deferred until the child has

*Correspondence: Dr P Borry, Center for Biomedical Ethics and Law - Box 7001, K.U. Leuven, Kapucijnenvoer 35/3, Leuven, 3000, Belgium.

Tel: + 32163369 51; Fax: + 32163369 52;

E-mail: Pascal.Borry@med.kuleuven.be

Received 19 April 2007; revised 6 July 2007; accepted 17 July 2007; published online 22 August 2007 matured. The minor's future autonomy tended to be the main ethical argument at stake. As the knowledge of carrier status is only important when the minor reaches reproductive age, the guidelines stated that it is wiser to defer testing until the minor himself is able to give proper informed consent to such a test rather than to acquiesce to the wishes of his parents or guardians to perform testing. However, the guideline of the British Medical Association ${ }^{2}$ and the position paper of the Genetic Interest Group ${ }^{3}$ (a national alliance of patient organisations with a membership of over 130 charities which support children, families and individuals affected by genetic disorders) underscored that the obstinate refusal to comply with a parental request for the carrier testing of a child (eg, in cases where the parents cannot deal with the anxiety of not knowing the carrier status of their child) may have a more negative 
impact on the child and his family than would complying with the request. Both statements also advanced that knowledge of one's carrier status could help a child to cope with this information starting in childhood and could reduce the anxiety and uncertainty experienced by parents about their child's carrier status. The GIG stated that 'after suitable counselling, parents have the right to make an informed choice about whether or not to have their children tested for carrier status. Ideally, children should only be tested when of an age to be involved in the decision.'

Despite the general presumption from the genetic services providers to defer carrier testing in minors, several studies $^{4-6}$ reported that genetic services are often confronted with parental requests to determine carrier status of healthy children and regularly accede to these requests. Most of these studies, ${ }^{4,5}$ however, have been performed in a period where professional recommendations on the issue were just published and might therefore not have been translated into practice at the time of the research. It has been reported ${ }^{7-10}$ that in certain countries (eg, Finland) it was common practice until the beginning of the 1990s to perform a carrier test on healthy children who were first degree relatives of affected individuals. Another relevant and recent study ${ }^{6}$ had only the level of a pilot study and consisted of a group of respondents of 12 pediatricians and 13 geneticists. In a previous study, we stressed the need for future empirical research into the views of the different stakeholders towards carrier testing in minors. ${ }^{11}$ Therefore, the aim of this study is to gather information from clinical geneticists about their practices and attitudes with regard to carrier testing in minors. This article will be focused on practices and attitudes regarding incompetent children.

\section{Methods \\ Sample}

With the help of the website orphanet (http://www. orpha.net), the websites of the national genetic associations and/or national contact persons a list of clinical institutes (at which genetic counseling is offered to patients) was generated. Institutes providing only laboratory services or providing only prenatal diagnosis were not within the scope of this survey and not included in the list from the $27 \mathrm{EU}$ Member States studied. In total 312 institutes were identified.

\section{Procedure}

From these institutes the e-mail and contact address of (mostly) the head of the institute were gathered. Every institute was contacted with the aim to receive one questionnaire back per institute. Medically qualified specialists in genetics (referred to hereafter as clinical geneticists) who have offered genetic counseling to patients in the last year were asked to complete a questionnaire of items assessing their attitudes and practices regarding genetic testing in minors. Every questionnaire contained a list of the institutes that were identified in their country and respondents were asked if they knew other institutes in their country that were not listed in the questionnaire. The data collection took place between October 2006 and March 2007. Two weeks after the questionnaire was sent out by e-mail, a reminder was made to non-responders. A second, third, fourth and sixth reminder by e-mail were sent out with approximate intervals of 2 weeks. The fifth reminder was sent by hard copy to the non-responders. No monetary or other incentive was offered.

\section{Questionnaire}

All respondents completed a 28-item questionnaire. The survey instrument was developed specifically for this study. The measures were based on ethical issues related to genetic testing in minors identified in the literature and from previous research. The selection of diseases covers a range of diseases that vary with regard the age of onset, severity and treatability. All questions in this article are related to carrier testing (heterozygous carrier testing of an autosomal recessive or X-linked genetic disorder) in incompetent minors. The questions were mostly linked to a 6-year-old child, as an exemplar of an incompetent minor whose parents or legal guardians have the legal authority. Using a five-point Likert response scale, respondents were directed to indicate whether they are '(very) willing or unwilling to provide carrier test to a 6-year-old child.' Using a five-point Likert response scale, the respondents were also directed to indicate whether they '(strongly) agree or disagree' with statements regarding the child's and the parental right to make this kind of decision, concerns regarding future autonomy and confidentiality, parental uncertainty and anxiety. The following sociodemographic and practice characteristics were also measured in the questionnaire: gender, age and country. Before sending the questionnaire, it was reviewed by 10 experts from various backgrounds (patient organizations, genetics, medicine, ethics, law, social sciences and nursing sciences).

\section{Statistical analysis}

As the survey responses were measured on an ordinal scale, non-parametric statistics were used. The analysis was performed using SAS 9.1.3. A two-tailed WilcoxonMann-Whitney $U$ test at a 0.05 significance level was used to compare differences in practices. Countries were divided into four groups based on geographical regions described by the United Nations: Western European countries (Austria, Belgium, France, Germany and the Netherlands), Eastern European countries (Bulgaria, Czech Republic, Hungary, Poland, Slovakia, Slovenia and Romania), Northern European countries (Denmark, Finland, Ireland, Latvia, Sweden, United Kingdom, Lithuania and 
Estonia) and Southern European countries (Spain, Greece, Italy, Malta, Portugal and Cyprus). Regional differences were studied using a two-tailed Wilcoxon-Mann-Whitney $\mathrm{U}$ test at a 0.01 level of significance. Although the questions were presented in a five-point Likert-type scale, this scale was recoded into a three-point scale for the statistical analysis. For the analysis of associations between two ordinal variables, the Spearman's rank correlation coefficient was used. This coefficient takes on a value between -1 and +1 and is a measure of an association between two ordinal variables. It is interpreted in a similar way to a correlation coefficient. For these statistics the fivepoint Likert-type scale was used.

\section{Results}

\section{Response rate and demographic characteristics}

Five supplementary institutes were identified from the respondents. Of the 317 institutes contacted, 17 institutes responded that they were only providing laboratory services, prenatal diagnosis or had finished their activities. Fourteen other institutes were excluded for the same reason, but on the indication of another respondent. Five institutes were also excluded because the staff member who responded to the questionnaire answered in the name of two institutes. Of the remaining 281 institutes, four respondents refused to complete the questionnaire. One hundred and seventy-seven respondents returned a completed questionnaire, corresponding to a response rate of $63 \%(177 / 281)$.

The mean year of birth of the clinical geneticists who answered the questionnaire was 1956 (SD 8.7), within the range 1934-1977. Forty-seven percent (84/177) of the respondents were women, 53\% (93/177) were men. We received in total responses from 26 different European countries.

\section{Practices regarding carrier testing in minors}

The questionnaire listed nine autosomal recessive and 10 X-linked disorders and asked respondents whether they have ever provided a carrier test to a minor younger than 16-year old. In Table 1, we present the responses of the clinical geneticists who have ever provided counseling for these disorders. For all diseases an overwhelming number of respondents reported that they had never provided such a test (range 64-97\%). For fragile X (36\%), cystic fibrosis (34\%) and Duchenne muscular dystrophy (28\%), the number of clinical geneticists who have provided such a test is significantly higher than in the other cases. The results of the Wilcoxon-Mann-Whitney $U$ test indicated, for example, that the respondents have provided significantly more carrier tests for Duchenne muscular dystrophy (28\%) than for deafness (connexin 26) (18\%) $(z=-2.0833)$, two-tailed $P=0.04)$.
Table 1 Frequencies and percentages of clinical geneticists who have ever provided a carrier test to a minor younger than 16-year old for the diseases for which they have themselves ever provided genetic counseling; frequencies of clinical geneticists who have never provided genetic counseling for that disorder

\begin{tabular}{lcc}
\hline & Yes & $\begin{array}{c}\text { Never provided } \\
\text { counseling }\end{array}$ \\
\hline$\alpha$-1-Antitrypsin deficiency & $15 \%(16 / 109)$ & 68 \\
Deafness (connexin 26) & $18 \%(25 / 138)$ & 39 \\
Aspartylglucosaminuria & $8 \%(1 / 13)$ & 164 \\
Sickle-cell anaemia & $14 \%(10 / 74)$ & 103 \\
Ataxia-telangiectasia & $8 \%(8 / 96)$ & 81 \\
Spinal muscular dystrophy & $12 \%(18 / 150)$ & 27 \\
$\beta$-Thalassemia & $19 \%(21 / 108)$ & 69 \\
Tay Sachs disease & $3 \%(2 / 71)$ & 106 \\
Cystic fibrosis & $34 \%(54 / 159)$ & 18 \\
Adrenoleukodystrophy & $8 \%(9 / 109)$ & 68 \\
G6PD deficiency & $12 \%(11 / 90)$ & 87 \\
Choroideremia & $5 \%(2 / 42)$ & 135 \\
Hemophilia A & $15 \%(21 / 137)$ & 40 \\
Duchenne muscular dystrophy & $28 \%(45 / 158)$ & 19 \\
Norrie disease & $10 \%(6 / 61)$ & 116 \\
Fabry disease & $19 \%(15 / 80)$ & 97 \\
Retinitis pigmentosa & $7 \%(10 / 136)$ & 41 \\
Fragile X syndrome & $36 \%(59 / 162)$ & 15 \\
X-linked severe combined & $4 \%(3 / 70)$ & 107 \\
immunodeficiency & & \\
\hline
\end{tabular}

\section{Clinical geneticists' opinions about carrier testing for recessive disorders}

Table 2 presents the clinical geneticists' opinions about the willingness to provide a carrier test to a 6-year-old child whose parents are both carriers of an autosomal recessive genetic disease and are requesting a carrier test for their child. The majority of the clinical geneticists were very unwilling or unwilling to provide a carrier test for the following disorders to a 6-year-old child on parental request: $\alpha$-1-antitrypsin deficiency $(63 \%)$, deafness (connexin 26) (72\%), aspartylglucosaminuria (78\%), sickle cell anemia (59\%), ataxia-telangiectasia (74\%), spinal muscular dystrophy (74\%), $\beta$-thalassemia (59\%), Tay Sachs disease (75\%) and cystic fibrosis (67\%). The results of WilcoxonMann-Whitney U tests showed that neither the sex of the respondents nor the fact that the clinical geneticist had already offered counseling for this disease influenced their responses. No statistically significant differences in answers were observed between Northern and Western European countries (eg, for cystic fibrosis, $Z=1.7254, P=0.09$ ), nor between Eastern and Southern European countries (eg, for cystic fibrosis, $Z=1.7105, P=0.09)$. However, many significant differences were observed between Northern and/ or Western European countries versus Eastern and/or Southern European countries. The results of the WilcoxonMann-Whitney $U$ test indicated that for almost all disorders, respondents from Eastern and Southern European countries are more willing to provide a carrier 
test to a 6-year-old child on parental request: $\alpha$-1-antitrypsin deficiency $(z=3.3739, P=0.0007)$, deafness (connexin 26) $(z=3.4104, P=0.0006)$, aspartylglucosaminuria $(z=4.0226, P<0.0001)$, ataxia-telangiectasia $(z=4.0870$, $P<0.0001)$, spinal muscular dystrophy $(z=3.4837$, $P=0.0005), \quad \beta$-thalassemia $(z=3.6004, P=0.0003)$, Tay Sachs disease $(z=3.6526, P=0.0003)$ and cystic fibrosis $(z=4.4156, P<0.0001)$. For sickle cell anemia no significant differences were observed.

\section{Clinical geneticists' opinions about carrier testing for $\mathrm{X}$-linked disorders}

Table 3 presents the clinical geneticists' opinions about the willingness to provide a carrier test to a 6-year-old girl whose mother is a carrier and is requesting a carrier test for her child. The majority of the clinical geneticsts were very unwilling or unwilling to provide a carrier test to a 6-yearold girl for the following X-linked disorders on parental request: adrenoleukodystrophy (83\%), G6PD deficiency (71\%), choroideremia (84\%), hemophilia A (77\%), Duchenne muscular dystrophy (81\%), Norrie disease (82\%), Fabry disease $(68 \%)$, retinitis pigmentosa $(80 \%)$, fragile $X$ (63\%) and X-linked severe combined immunodeficiency (77\%). The results of Wilcoxon-Mann-Whitney U tests showed that neither the sex of the respondents nor the fact that the clinical geneticist had already offered counseling for this disease influenced their responses. As with the autosomal recessive disorders, the results of the WilcoxonMann-Whitney $U$ test indicated that for almost all $\mathrm{X}$-linked disorders, respondents from Eastern and Southern European countries are more willing to provide a carrier test to a 6-year-old child on parental request: adrenoleukodystrophy $(z=4.7096, P<0.0001)$, G6PD deficiency $(z=4.5409, \quad P<0.0001), \quad$ choroideremia $\quad(z=3.9937$, $P<0.0001)$, hemophilia A $(z=3.9465, P<0.0001)$, Duchenne muscular dystrophy $(z=3.5402, P=0.0004)$, Norrie disease $(z=3.7816, \quad P<0.0002)$, retinitis pigmentosa $(z=3.9148, P<0.0001)$, fragile $X(z=4.5280, P<0.0001)$ and $X$-linked severe combined immunodeficiency $(z=4.3330, P<0.0001)$. For Fabry disease no significant differences were observed.

Experience and arguments of clinical geneticists about carrier testing in minors

As we can see in Table 4, the respondents expressed different views about the question regarding whether it is their experience that parents prefer to delay carrier testing of their children until their children can decide for themselves. Although 47\% strongly agreed or agreed somewhat with this statement, $41 \%$ strongly disagreed or disagreed somewhat. Seventy-nine percent of the clinical geneticists strongly disagreed or disagreed somewhat that parents should have the right to decide if their 6-year-old child should be tested for carrier status. In addition, $78 \%$ of the clinical geneticists strongly disagreed or disagreed 
somewhat that parental uncertainty and anxiety is a good reason to perform a carrier test. The responses showed also concerns for the future autonomy and the confidentiality of the child. Sixty-seven percent of the respondents strongly agreed or agreed somewhat with the statement that the future autonomy is violated if a carrier test is performed and the test result provided to the parents, $62 \%$ with the statement that the confidentiality is violated if a carrier test is performed on a 6-year-old child. However, respectively $17 \%$ and $23 \%$ of the clinical geneticists do not hold this position. Age and gender did not influence the responses. However, the results of the Wilcoxon-MannWhitney $U$ test indicate that clinical geneticists from Southern and Eastern European countries are significantly less likely to agree that the future autonomy $(z=-3.6527$, $P=0.0003)$ and the confidentiality of genetic information $(z=-3.4286, P=0.0006)$ is violated if a carrier test is provided on a 6-year-old child.

To investigate the associations between the abovementioned scale scores and the responses to the questions regarding whether clinical geneticists would perform a carrier test on a 6-year-old child for an autosomal recessive or X-linked disease, Spearman's rank correlation coefficients were calculated. As an example, we integrate here the results for spinal muscular dystrophy, but the described trend is present in all autosomal recessive and X-linked disorders. The Spearman's rank correlation coefficients showed that when a clinical geneticist was unwilling to perform such a test, he/she mostly disagreed that parental uncertainty and anxiety was a good reason to perform a carrier test $\left(r_{\mathrm{s}}=0.39010, P<0.0001\right)$, he/she mostly disagreed that parents should have the right to decide about such a test $\left(r_{\mathrm{s}}=0.45855, P<0.0001\right)$, he/she mostly agreed that future autonomy $\left(r_{\mathrm{s}}=-0.43973, P<0.0001\right)$ and the confidentiality of genetic information is violated if this test is performed $\left(r_{\mathrm{s}}=-0.39249, P<0.0001\right)$.

\section{Discussion}

The survey shows that most of the respondents would delay carrier testing in young children until the child can decide as an adult to have a carrier test. Most respondents also agree that testing of incompetent minors denies the future autonomy of the child and his ability to decide later in life whether to undergo such testing, and breaches the confidentiality of the child's genetic information. In general, the survey showed a strict adherence to existing recommendations and guidelines regarding carrier testing in incompetent minors. ${ }^{1}$ The German Society of Human Genetics, ${ }^{12}$, for example, stated: 'An investigation for the sole purpose of determining carrier status for a recessively inherited illness or a balanced familial chromosomal translocation should not be carried out since the results would only be significant for future reproductive decisions 
Table 4 Frequency of responses to item

\begin{tabular}{|c|c|c|c|c|c|}
\hline & $\begin{array}{l}\text { 1. Strongly } \\
\text { disagree }\end{array}$ & $\begin{array}{l}\text { 2. Disagree } \\
\text { somewhat }\end{array}$ & $\begin{array}{l}\text { 3. Neither agree } \\
\text { or disagree }\end{array}$ & $\begin{array}{l}\text { 4. Agree } \\
\text { somewhat }\end{array}$ & 5. Strongly agree \\
\hline $\begin{array}{l}\text { It is my experience that parents prefer to delay carrier } \\
\text { testing of their children until their children can decide } \\
\text { for themselves }\end{array}$ & $10 \%(17 / 174)$ & $31 \%(55 / 174)$ & $12 \%(21 / 174)$ & $34 \%(59 / 174)$ & $13 \%(22 / 174)$ \\
\hline $\begin{array}{l}\text { Parents have the right to decide if their } 6 \text {-year-old child } \\
\text { should be tested for carrier status }\end{array}$ & $51 \%(90 / 176)$ & $28 \%(50 / 176)$ & $6 \%(10 / 176)$ & $11 \%(19 / 176)$ & $4 \%(7 / 176)$ \\
\hline $\begin{array}{l}\text { Parental uncertainty and anxiety about potential carrier } \\
\text { status of their 6-year-old child is a good reason to } \\
\text { perform a carrier test }\end{array}$ & $44 \%(77 / 175)$ & $34 \%(59 / 175)$ & $7 \%(12 / 175)$ & $11 \%(19 / 175)$ & $4 \%(8 / 175)$ \\
\hline $\begin{array}{l}\text { The future autonomy of a 6-year-old child is violated if a } \\
\text { carrier test is performed on a } 6 \text {-year-old child and the } \\
\text { test result provided to the parents }\end{array}$ & $5 \%(9 / 175)$ & $12 \%(21 / 175)$ & $16 \%(28 / 175)$ & $30 \%(53 / 175)$ & $37 \%(64 / 175)$ \\
\hline $\begin{array}{l}\text { The confidentiality of genetic information is violated if a } \\
\text { carrier test is performed on a } 6 \text {-year-old child and the } \\
\text { test result provided to the parents }\end{array}$ & $8 \%(14 / 174)$ & $15 \%(27 / 174)$ & $15 \%(26 / 174)$ & $36 \%(62 / 174)$ & $26 \%(45 / 174)$ \\
\hline
\end{tabular}

of the child him/herself.' The European Society of Human Genetics ${ }^{13}$ stated 'tests for carrier status should be delayed until the person is old enough to make an informed choice.'; and the Japanese Society of Human Genetics. ${ }^{14}$ 'With a view to protecting their future autonomous decision-making, carrier detection for children should not be done.'

However, we observed that for every condition studied, a minority of clinical geneticists (range 9-27\%) were willing or very willing to provide a carrier test to a 6-year-old child on parental request. Fifteen percent of the clinical geneticists also agreed somewhat or strongly agreed that parents have the right to decide if their 6-year-old child should be tested for carrier status; $15 \%$ agreed somewhat or strongly agreed that parental uncertainty and anxiety is a good reason to perform a carrier test; $17 \%$ also somewhat disagreed or strongly disagreed that the future autonomy of a 6-year-old child is violated if the carrier test is performed; and 23\% somewhat disagreed or strongly disagreed that the confidentiality of genetic information would be violated in this situation. A similar percentage of clinical geneticists (range 3-36\%) have already provided carrier tests to a minor younger than 16 years.

Geographical differences were found with regard to these responses. About one-third of the respondents (range 22$46 \%$ ) from Southern and Eastern European countries were very willing or willing to provide a carrier test for an autosomal recessive or X-linked disorder. There are several possible explanations for these differences. Firstly, the fact that in various countries the specialty of medical genetics is not recognized. It is clear that the structure and limitations of health-care systems as well as the specific expertise of the clinical geneticist have an influence on the quality and harmonization of genetic counseling. ${ }^{15}$ Secondly, all clinical guidelines and position papers collected ${ }^{1}$ have been written in English, and originate from countries in Northern or Western Europe; or from the United States,
Japan and Canada. Although globalization and international cooperation characterizes the field of genetics, it might be that clinical geneticists are influenced by the cultural background in which they live. A survey of professionals in 37 countries by Wertz ${ }^{16}$ revealed that the majority of geneticists in Northern and Western part of Europe, the USA, and other English speaking countries would refuse predictive testing of minors for adult onset diseases but in Asia, Latin America, and the Southern and Eastern part of Europe, the majority of geneticists would accede to parental requests. Previous research ${ }^{17}$ showed that many respondents from Latin America, Southern Europe, Eastern Europe, the Near East, and Asia responding to a survey about genetic testing answered both 'I would preserve the patient's confidentiality' and 'I would tell relatives if they ask.' They proceeded to explain that these answers were not contradictory, because they were only overriding confidentiality if they told relatives who did not ask or told employers or insurers. This may be explained by the respondents regarding the unit of privacy as the family rather than the individual. At the first sight this seems to correspond with various authors ${ }^{18}$ who have emphasized the familial nature of genetic information. Wachbroit ${ }^{19}$ commented that the family, rather than an individual patient, is the real patient in the case of hereditary diseases. However, these statements on the familial character of genetic information are mostly regarding diseases where preventive or therapeutic measures may avert the development of the disease rather than the situation of carrier testing. Thirdly, some clinical geneticists may believe that refusing to comply with a parental request for carrier testing in their children may have a more negative impact on the child and its family than acceding to the request. It has been proposed that those individuals who turn out to be non-carriers can be relieved from the uncertainties and anxieties related to their risk status. This positive news can protect them from erroneous assumptions of being a 
carrier. $^{20}$ It has also been pointed out that learning the carrier status early in life may facilitate anticipation of the future and appropriate planning, avoiding a possible shock if the carrier status is only discovered later in life. ${ }^{21}$ Finally, it has been asserted that for some carrier testing for $\mathrm{X}$-linked conditions may predict disease in the individual. For example, Fragile $X$ carrier testing in a female may predict the risk of premature ovarian failure and FAXTAS. ${ }^{22}$

\section{Conclusion}

In general, the survey showed an adherence to existing recommendations and guidelines regarding carrier testing in incompetent minors. However, for every condition studied, a group of clinical geneticists, particularly from Southern and Eastern European countries, was willing or very willing to provide a carrier test to a 6 -year-old child on parental request. These significant geographical differences might be explained by structural, cultural as well as contradicting ethical positions. If clinical geneticists want to develop a more common European approach in this area, professional policy actions will have to be undertaken.

\section{Acknowledgements}

The research for this contribution was supported by the Eurogentest Network of Excellence of the EU, FP6-512148.

\section{References}

1 Borry P, Schotsmans P, Fryns JP, Dierickx K: Carrier testing in minors: a systematic review of guidelines and positions statements. Eur J Hum Genet 2006; 14: 133-138.

2 British Medical Association: Human genetics: choice and responsibility. Oxford: University Press, 1998.

3 Dalby S: GIG response to the UK clinical genetics society report 'the genetic testing of children'. J Med Genet 1995; 32: 490-491.

4 Wertz DC, Reilly PR: Laboratory policies and practices for the genetic testing of children: a survey of the Helix network. Am J Hum Genet 1997; 61: 1163-1168.
5 Balfour-Lynn I, Madge S, Dinwiddie R: Testing carrier status in siblings of patients with cystic fibrosis. Arch Dis Child 1995; 72: $167-168$.

6 Campbell E, Ross LF: Professional and personal attitudes about access and confidentiality in the genetic testing of children: a pilot study. Genet Test 2003; 7: 123-130.

7 Jarvinen $\mathrm{O}$, Lehesjoki AE, Lindlof $\mathrm{M}$, Uutela A, Kaariainen $\mathrm{H}$ Carrier testing of children for two $\mathrm{X}$ linked diseases in a family based setting: a retrospective long term psychosocial evaluation. $J$ Med Genet 1999; 36: 615-620.

8 Jarvinen $\mathrm{O}$, Lehesjoki AE, Lindlof $\mathrm{M}$, Uutela A, Kaariainen $\mathrm{H}$ : Carrier testing of children for two X-linked diseases: a retrospective evaluation of experience and satisfaction of subjects and their mothers. Genet Test 1999; 3: 347-355.

9 Jarvinen O, Hietala M, Aalto AM et al: A retrospective study of long-term psychosocial consequences and satisfaction after carrier testing in childhood in an autosomal recessive disease: aspartylglucosaminuria. Clin Genet 2000; 58: 447-454.

10 Jarvinen $\mathrm{O}$, Lehesjoki $\mathrm{AE}$, Lindlof $\mathrm{M}$, Uutela $\mathrm{A}$, Kaariainen $\mathrm{H}$ : Carrier testing of children for two X-linked diseases: A retrospective study of comprehension of the test results and social and psychological significance of the testing. Pediatrics 2000; 106: $1460-1465$

11 Borry P, Schotsmans P, Fryns JP, Dierickx K: Attitudes of minors, parents and health professionals towards carrier testing in minors: a systematic review. Genet Couns 2005; 16: 341-352.

12 German Society of Human Genetics: Statement on genetic diagnosis in children and adolescents 1995, http://www.gfhev.de/en/.

13 European Society of Human Genetics: Provision of Genetic services in Europe - current practices and issues 2001, http://www.eshg.org.

14 Japan Society of Human Genetics: Guidelines for Genetic Testing. J Hum Genet 2001; 46: 163-165.

15 Ibarreta D, Bock AK, Klein C, Rodriguez-Cerezo E: Towards quality assurance and harmonisation of genetic testing services in the EU. Sevilla. JRC-IPTS, 2003.

16 Wertz DC: International perspectives; In: Clarke A (ed): The Genetic Testing of Children. Oxford: Bios, 1998, pp 271-289.

17 Wertz DC: No consensus worldwide. Am J Bioethics 2001; 1: $14-15$.

18 Doukas DJ, Berg JW: The family covenant and genetic testing. Am J Bioethics 2001; 1: 2-10.

19 Wachbroit R: Rethinking medical confidentiality: The impact of genetics. Suffolk University Law Rev 1993; 27: 1391-1410.

20 Fanos JH: Developmental tasks of childhood and adolescence: implications for genetic testing. Am J Med Genet 1997; 71: 22-28.

21 Michie S, Marteau T: Predictive genetic testing in children: the need for psychological research; In: Clarke A (ed).: The Genetic Testing of Children. Oxford: Bios, 1998, pp 169-182.

22 Sherman SL: Premature ovarian failure in the fragile X syndrome. Am J Med Genet 2000; 3: 189-194. 